\title{
PENSATA
}

\section{UNIVERSIDADE CORPORATIVA: GÊNESE E QUESTÕES CRÍTICAS RUMO À MATURIDADE}

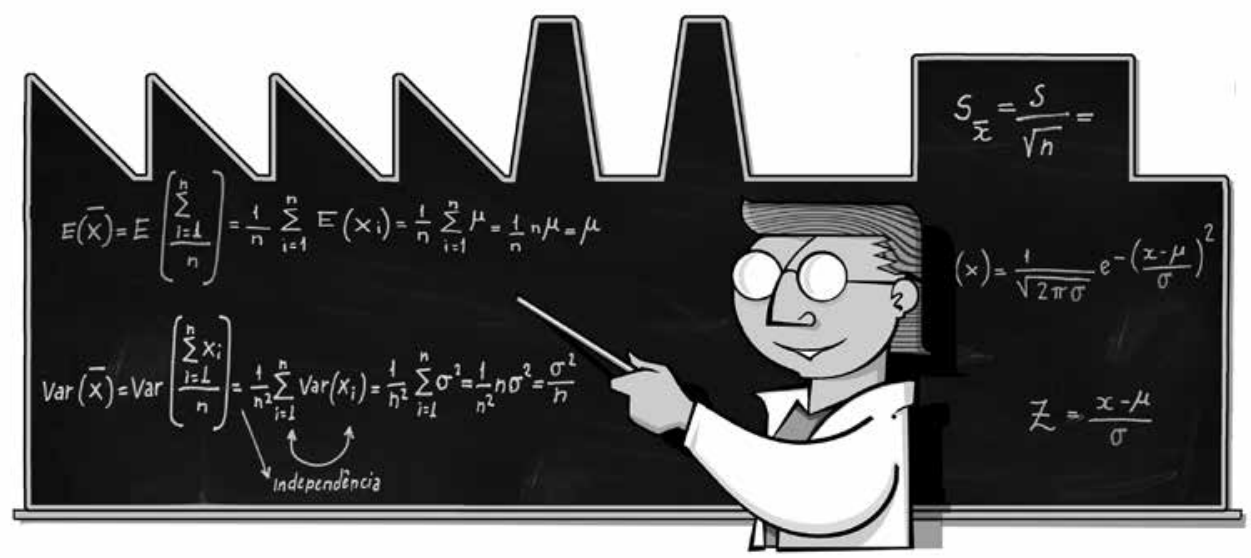

O atual momento econômico do País e a aflição diante dos desafios de organizar a Copa do Mundo e as Olimpíadas colocam em evidência a extrema importância de capacitar e educar pessoas. De fato, todas as empresas preocupadas com real desenvolvimento sabem que este não será possível sem a formação permanente dos seus quadros.

No Brasil, o desafio é ainda maior, pois as empresas precisam também lidar com as falhas de nosso sistema educacional. Apesar de sermos a sétima maior economia do mundo, ainda temos um dos piores desempenhos entre a meia centena de países que participam do Program for International Student Assessment (PISA). Somos um "trem-bala“ com maquinistas de "maria-fumaça”.

Nesse particular, as universidades corporativas brasileiras - assunto do presente ensaio têm uma dupla missão. Devem fazer o que fazem todas, ou seja, avançar a competência profissional dos seus quadros. Mas, também, corrigir lacunas resultantes de um sistema educacional claudicante, para ser generoso com ele.

Diante disso, assustam os desafios relativos à formação de pessoas. Não por acaso, a preocupação com mão de obra (disponibilidade, custo e qualificação) chegou ao topo da lista de temores dos executivos que comandam grandes empresas brasileiras, seja na indústria, no varejo ou em serviços.

O guia As Melhores Empresas para Você Trabalhar 2012, publicado pela Revista Você S/A, re-

\section{CLAUDIO DE MOURA CASTRO}

claudiodemouracastro@positivo.com.br Economista pela Faculdade de Ciências Econômicas, Universidade Federal de Minas Gerais. Assessor da Presidência do Grupo Positivo - Curitiba - PR, Brasil

\section{MARISA EBOLI}

marisap@fia.com.br

Professora e Coordenadora de Projetos da Fundação Instituto de Administração - São Paulo - SP, Brasil força o coro de que o Brasil é um país que continua carente de mão de obra qualificada. Um dado interessante dessa edição foi mostrar a ênfase em promover talentos dentro da empresa, uma realidade para as 150 melhores. Inevitavelmente, quanto mais se promove internamente, maior a necessidade de se investir em formação.

Também a pesquisa “Dez Empresas mais Admiradas no Brasil”, da Revista Carta Capital (2012), traz resultados nessa linha, mostrando que, entre elas, nove têm Universidades Corporativas (UCs) ou Sistemas de Educação Corporativa (SECs), como também são chamadas.

Há uma estreita associação entre educação, modernidade e competitividade nas empresas.

Ao longo desses anos, surpreende ver quanto esse assunto ganhou preeminência, seja nas empresas públicas ou privadas, ou mesmo dentro das universidades tradicionais. Portanto, não 
dá a impressão de ser um modismo, mas um braço essencial das empresas modernas e bem-sucedidas. Vale a pena entender meIhor o que vem a ser, de fato, uma UC.

\section{FILOGÊNESE DA UNIVERSIDADE CORPORATIVA}

Biólogos chamam de filogênese o conjunto de modificações e adaptações que vão, progressivamente, transformando uma espécie existente em uma nova. Será que podemos usar essa metáfora para falar das UCs? Achamos que sim. De fato, parece haver uma trajetória significativa e comum, quando olhamos para o conjunto de instituições apelidadas de UCs.

Com as devidas cautelas, prossigamos. O antepassado da UC é o Centro de Treinamento \& Desenvolvimento. Não é de hoje que as boas empresas perceberam não ser possível conseguir, prontos no mercado, exatamente os perfis ocupacionais de que precisam. Já na Alemanha do século XIX, as fábricas começaram a estruturar programas de aprendizagem para os jovens contratados - incluindo linguagem e matemática.

Não tardou muito, uma grande variedade de iniciativas para formação e aperfeiçoamento começou a se estruturar. Pode ser porque não havia os perfis desejados no mercado, ou não tinham a qualidade exigida, ou custavam muito caro. No Brasil, foram as estradas de ferro que criaram os primeiros e mais sofisticados Centros de Treinamento. Hoje, praticamente não há empresa de porte que não o tenha, embora possam apresentar diferentes nomes, graus de complexidade e ambição.

Com o passar do tempo, os objetivos do Centro de Treinamento alargaram-se. Claro, se a empresa precisa de quem pregue pregos, vai continuar oferecendo cursos ensinando a pregar pregos. Mas uma organização é um ente vivo, com valores, crenças, hábitos e preferências. Para ser um bom funcionário, é preciso internalizar toda essa carga não cognitiva. Daí que, junto ao ensino de pregar pregos - ou o que seja - a empresa "converte" os novos funcionários aos seus valores. Há que transmitir a cultura da empresa.

Um bom exemplo é o da Motorola University (MU, cujas raízes foram fincadas em 1980). Nela, cerca de 30\% dos cursos foram criados para atender aos objetivos gerais da empresa. Esses cursos introduziam funcionários na "cultura Motorola", em questões éticas e nas práticas de qualidade (Six Sig$m a$ ). Os outros $70 \%$ foram desenhados para atender às necessidades específicas de negócios das várias divisões da empresa.

Em sociedades que se industrializam ou que têm forte migração rural-urbana, há que internalizar nos funcionários os valores do mundo empresarial, começando pelos hábitos de chegar na hora e o trato sereno com a hierarquia.

Outro exemplo nessa direção é a Hamburguer University (McDonald's), que tem como missão ser o polo de cultura organizacional da empresa. Para isso, oferece um processo contínuo de educação, em toda a cadeia de valor, capaz de transformar conhecimentos e atitudes em resultados para o negócio. Oferece aos jovens iniciantes programas básicos sobre higiene e saúde (uma vez que muitos são oriundos de classes mais humildes), para que estejam aptos a lidar com produtos, processos e equipamentos, de acordo com os padrões exigidos pela empresa. Essa é uma das suas ações para se garantir a excelência operacional, sempre professada pela organização.

Interessante notar que o mercado valoriza os graduados desses programas, ao deixarem a empresa. Como os conhecimentos operacionais adquiridos não servem para outras tarefas (o que os economistas chamam de "treinamento específico"), se esses jovens têm mais valor de mercado, isso terá que ser pela aquisição de hábitos, disciplina e valores do trabalho, todos traços categorizados como não cognitivos. A transmissão dessa carga de valores é a segunda etapa na filogênese.
Continuando nessa linha, se há os que pregam pregos, haverá também os que mandam neles. Portanto, o treinamento não pode parar na "pregologia”. Progressivamente, as técnicas e princípios de gestão entram no rol dos assuntos que é preciso transmitir. Ainda há aqueles que se lembram do Training Within Industry (TWI), o primeiro curso oferecido a supervisores de linha, então chamados de capatazes, que foi criado em 1941 por comissão do Departamento de Guerra dos Estados Unidos (fonte: http://twi-institute.com).

Portanto, na filogênese da UC, depois da pregologia e da disseminação de valores, vamos a essa terceira fase, em que a gestão passa a fazer parte do cardápio. Como esse é um tema complexo e multifacetado, vira assunto palpitante e controverso. Não se discute demasiado o curso de pregar pregos ou de fresa. Mas debater as seitas e religiões da gestão ocupa a vida de muita gente.

Essa etapa dos cursos gerenciais ocupa muito tempo e consome amplos recursos da empresa. Há muita gente para ser preparada para as sempre delicadas e críticas tarefas de mandar nos outros e coordenar essas ações com o restante da empresa.

Matricular o coordenador ou o encarregado no curso de gestão não oferece maiores desafios. Mas, quando começamos a querer pescar peixes mais graúdos, começam a aparecer relutâncias e vaidades. Trazer gerentes para fazer cursos onde operários também aprendem não é uma proposta convincente. Conseguir matricular os executivos é uma perspectiva ainda mais longínqua.

Nesse momento, entra a magia da semântica. Com nomes diferentes, as mesmas coisas passam a ser mais sedutoras. Em vez de Centro de Treinamento, por que não Universidade Corporativa? São outras emanações, outros significados, outra semiótica. E assim nasce a UC, o quarto degrau na filogênese da preparação de pessoal na empresa.

Com esse salto para cima na clientela, outros assuntos entram em pauta. É sem- 
pre preciso ensinar a fazer e a mandar, mas, agora, é preciso também ampliar a visão dos executivos. Isso inclui abrir horizontes, burilar uma leitura do mundo mais refinada e melhores antenas para captar o mundo exterior e lidar com ele. Para empresas que dependem dos ventos imprevisíveis da política e da economia, é preciso entender a meteorologia política.

Um exemplo claro é o crescimento na importância dos temas de meio ambiente. Se a empresa não tem radares minimamente competentes, não perceberá a importância de evitar erros e cuidar de suas vulnerabilidades, diante dos novos fundamentalismos nessa área.

Tudo isso se resume em aumentar a cultura dos executivos. Sempre é difícil definir cultura, mas não podemos ser totalmente céticos, quando vemos que as maiores empresas do mundo mandam seus executivos para seminários em que se discutem os Great Books da Britânica. Esse é o caso dos seminários executivos do Aspen Institute, um fórum com discussões e reflexões de obras selecionadas de escritores clássicos e modernos, para que os líderes entendam melhor os desafios enfrentados por suas organizações.

Seguindo a linha filogenética da aquisição de novos papéis, aparece um quinto degrau. Além de informar, formar, inculcar valores e preparar para a gestão, algumas UCs entram em uma fase de catalisar mudanças institucionais. Em perfeita sincronia com a alta administração, passam a ter um papel na orquestração do processo de mudança organizacional. Cursos, seminários, dinâmicas de mudança e implementação fundem-se num processo sem fronteiras claras entre a empresa e sua UC. Nessa fase, já não fica nítido quem faz o quê e onde as coisas acontecem. Além de instilar os novos valores e preparar para a mudança, há um novo papel de coadjuvante na implementação das mudanças propostas.

Em primeiro lugar, o Centro de Treinamento e a UC podem permanecer como en- tidades mais ou menos separadas. Isso não muda a natureza do processo evolutivo, é um mero detalhe administrativo. Por outro lado, é difícil imaginar muitos casos de empresas que criam UCs sem haver realizado um programa de treinamento do seu pessoal operativo.

Contudo, é natural e esperado que nem todas as UCs já tenham chegado à etapa final dessa filogênese. Para ilustrar, fala-se muito na GE como um exemplo para todos. Charles Coffin, presidente da empresa GE de 1892 a 1922, foi o responsável pela implantação da meritocracia baseada em avaliação de performance, que se tornou a pedra fundamental de uma cultura que transformou a GE numa máquina de fazer talentos. Sua UC, Crotonville, revelouse uma importante ferramenta na consolidação dessa cultura, na qual é muito forte o compromisso do líder com processos de gestão de pessoas.

\section{O QUE DEVE SER A UNIVERSIDADE CORPORATIVA}

Na presente seção, examinamos as linhas possíveis, aconselháveis e problemáticas para as UCs.

\section{É preciso foco}

Uma universidade tradicional tem linhas claras e bem trilhadas acerca do que é próprio às suas atividades. Faz ensino superior, pode fazer pesquisa e pouco mais do que isso. Essa é a sua raison d'être. Uma empresa produz automóveis ou edifícios, esse é o seu fim.

Em contraste, a UC é um instrumento, um meio para fazer melhor as suas atividades-fim. Portanto, não há recursos ou energias emocionais ilimitadas para cuidar dela. Daí a necessidade de foco nas suas atividades, para não perder-se em uma coleção de atividades desconectadas e que requerem considerável atenção.
Ou seja, o que caracteriza a educação corporativa é sua vinculação estratégica com a vida da empresa. Com efeito, os programas, os cursos e as ações educacionais devem ser concebidos e desenhados para bem atender à estratégia do negócio, olhando igualmente para o futuro e para fora da organização. Naturalmente, isso significa que não há fórmulas prontas. É preciso afiná-los, com ênfase no negócio e no setor de atuação da empresa. E, principalmente, todas as soluções educacionais devem refletir sua cultura organizacional.

Mais ou menos os mesmos cursos podem estar sendo oferecidos em programas abertos de mercado. Mas uma boa UC é justamente a que oferece soluções de aprendizagem com aspectos customizados, desenvolvendo as competências estratégicas que garantirão o sucesso da organização.

Passa a ser central a ideia de competências críticas (ou core competences), como capacidades que a empresa precisa possuir para garantir seu sucesso no mercado. Sua missão é dar ênfase ao seu próprio negócio e cultura. Ou seja, é preciso desenvolver competências nas pessoas que permitam diferenciar a empresa perante o mercado, na hora de competir.

\section{É universidade mesmo?}

O nome Universidade Corporativa é uma alegoria, uma fantasia. Cumpre muito bem o seu papel de inspirar, de criar a imagem de ferramenta de gestão de "alto nível".

Mas está longe de ser uma universidade, quer juridicamente, quer nas suas atividades. Se fosse universidade, de verdade, teria ainda mais status. Mas também estaria subjugada a uma legislação barroca e disfuncional. É o mundo do "não pode" e dos meandros do burocratismo exacerbado.

Por não ser realmente uma universidade, ganha vantagem em muitas direções. Pode montar os cursos que precisar, sobre o assunto que interessar, com a duração que parecer apropriada em cada caso. Não tem que dar satisfações a nenhuma legis- 
lação. Pode contratar quem quiser, e seus cursos não estão sob os grilhões da imposição de mestres e doutores. Terminado o curso, se quiser, encomenda um certificado de conclusão.

Vale a pena insistir nesse ponto, pois muitos professores universitários acabam na órbita das UCs. Nada errado, pelo contrário. Mas o cachimbo faz a boca torta, e é preciso cuidar para que não se implementem os mesmos ritos e liturgias que nem nas universidades tradicionais fazem sentido.

\section{DEVE OPERAR EM FUNÇÃO DA LÓGICA PRODUTIVA E NÃO DA RESPONSABILIDADE SOCIAL}

O Brasil é um país injusto e desigual. Diante desse cenário, bem como das suas consequências práticas, os brasileiros de vida confortável sentem-se envergonhados e embaraçados com essa característica da sua sociedade. Aqui batizamos essa culpa com o apelido de Síndrome de Gini.

Temos pena dos que têm pouco ou têm menos. Nada mais justificado do que tal sentimento. Contudo, o desarranjo começa se tentarmos consertar no local errado esse defeito da nossa sociedade.

Daí a contaminação das decisões de treinamento pela Síndrome de Gini. Tentase introduzir um componente social nas decisões de quem deve ser preparado e em que assunto. E isso acaba tendo consequências negativas.

O objetivo precípuo e central da UC é aumentar a produtividade e a competitividade da empresa. Tudo mais fica de fora ou tem um papel secundário. Como regra geral, só se deve oferecer aquele curso ou outra solução de aprendizagem se há boa chance de ser usado no trabalho ou ter impacto nos negócios. Isso vai de destrezas manuais até leituras do clima político. Ou seja, não defendemos aqui uma correspondência mecânica e óbvia entre curso e trabalho. Mas é preciso que se identifique um uso provável para o aprendido. 0 simples desejo de "fazer o bem" compromete a eficácia da UC e não promove a equidade, pois não resulta em nada do ponto de vista da competitividade.

Temas sociais não são irrelevantes ou assuntos a serem esquecidos. Só que as iniciativas para lidar com eles devem emanar de outro segmento da empresa. Universidade Corporativa não é orfanato, não é instituição de caridade, não é o braço social da empresa e não é mecanismo compensatório.

Sua função é cumprir o outro e maior “papel social” da empresa, que é produzir, ser competitiva, dar lucro, investir, crescer e engrandecer o País. Nunca é demais insistir na tese de que filantropia não pode ser função prioritária de uma empresa.

\section{Quem deve ser treinado?}

Observando as melhores empresas, suas escolhas são mais ou menos óbvias e fazem muito sentido. A UC não pode atender a todo seu pessoal, oferecer cursos de tudo para todos. Portanto, muitos dos conhecimentos detidos pelos funcionários terão sido adquiridos fora, sobretudo antes de serem contratados. Ou, então, são aprendidos de maneira espontânea e autodidata pelos funcionários.

Como regra simples, a empresa busca no mercado pessoas que já receberam tanto treinamento quanto o mercado pode oferecer. Não há boas razões para preparar um torneiro, da estaca zero. O Senai faz isso com distinção. Portanto, é boa política contratar os melhores torneiros que a empresa consegue atrair. E, assim, para todas as outras ocupações.

Contudo, a empresa pode ter tornos muito especializados, para os quais não há cursos sendo oferecidos no mercado. Portanto, terá todo o interesse em montar programas para operar tais máquinas.

O mesmo princípio é válido, também, para uma empresa, digamos, em Belo Mon- te, só que lá não há quem conheça minimamente as ocupações clássicas. Portanto, pode até ser necessário formar torneiros. Ainda assim, sobrevive o princípio de contratar pessoal com toda a preparação que o mercado pode oferecer e complementá -la nos assuntos em que nada é oferecido. Ou seja, o curso lapida as competências encontradas no mercado, mas estas variam de acordo com a geografia.

A empresa pode preferir contratar gente mais jovem, que amadurecerá no trabalho. Ou, então, optar por pessoas já confirmadas na profissão. Essas são estratégias empresariais às quais os cursos oferecidos têm que se adaptar. Mas tais diferenças de estratégias não mudam a lógica do seu funcionamento.

\section{Acima de tudo, não matar a galinha dos ovos de ouro}

$\mathrm{Na} \mathrm{GE}, 80 \%$ do que se aprende é no local de trabalho, com líderes, supervisores e colegas, de acordo com apresentação feita por Paul Fama, Diretor Executivo de Recursos Humanos da GE para América Latina, no 2ํㅗ Simpósio Internacional de Educação Corporativa realizado pela FIA, em 13 de novembro de 2012 (vídeo on-demand: http:// v3.webcasters.com.br/Login.aspx?codTransmissao $=110788$ ). Portanto, só $20 \%$ vêm dos cursos oferecidos.

Insiste-se, também, em que a aprendizagem na prática é melhor.

Nada há de equivocado nessa estratégia. Mas é preciso não a entender erroneamente. A excelência só é obtida aprendendo com quem já atingiu os píncaros da competência. Se tais pessoas estão na empresa, ótimo, faça-se como na GE. Se não estão, cursos bem-estruturados são a maneira de importar essa excelência. Além do que, conforme a ocupação, oferecem a garantia de uma formação permanente, homogênea e sistematizada. Resumindo, os $80 \%$ aprendidos na prática só funcionam bem se esses $20 \%$ estiverem sendo usados para completar as competências ausentes. 
Não se pode matar a galinha dos ovos de ouro, fazendo economia na operação dos cursos. Ou se aprende com quem sabe muito, ou a empresa sai lesada.

\section{RISCOS E TROPEÇOS}

Nosso diagnóstico pode avançar mais, além de conjecturas, pois hoje dispomos de algumas pesquisas sistemáticas das UCs brasileiras. No geral, mostram resultados bastante positivos, confirmando as hipóteses otimistas acerca do seu desempenho. Mas mostram também deficiências. É sobre elas que se concentram nossas observações, pois, sem uma boa compreensão do que está errado, não há como buscar correções.

Recentemente, a Fundação Instituto de Administração (FIA) realizou a segunda Pesquisa Nacional sobre Práticas e Resultados da Educação Corporativa (2012), com uma amostra de 60 empresas. Sua principal constatação é que a educação corporativa no Brasil caminha para a consolidação, embora alguns aspectos precisem ser aprimorados.

A primeira crítica às UCs é que são frágeis os seus mecanismos internos de avaliação dos resultados obtidos. Admitamos, não é fácil conduzir avaliações de impacto de cursos para formação e demais soluções de aprendizagem. Entre outras razões, porque tendem a ser oferecidos quando tudo está mudando, sejam equipamentos ou práticas de gestão. Isso nos leva aos clássicos problemas de imputação dos economistas. Se tudo muda, como descobrir o que faz o que mudar? Não obstante, há muito a ser feito para institucionalizar os mecanismos de avaliação de uma UC.

Outro ponto crítico, como mencionado anteriormente, é a contaminação das decisões de formação pela Síndrome de Gini. $\mathrm{Na}$ prática, ofereceríamos educação sem que houvesse boa probabilidade de o destinatário do curso usar o que aprendeu: “Coi- tadinho, tem tão poucas oportunidades, vamos deixá-lo fazer o curso". O resultado é que se gastam recursos e não há uso para o conhecimento adquirido. Portanto, quem fez o curso sai ainda mais frustrado do que antes, e o orçamento da UC é queimado em uma atividade improdutiva.

Essa é uma característica recorrente dos nossos sistemas de educação, captada por um dos autores em um estudo realizado com grandes empresas, na década de 1970. Descobriu-se que as empresas multinacionais só treinavam se havia claro uso para o conhecimento oferecido pelo curso. Em contraste, nas empresas brasileiras havia uma grande liberalidade, deixando que os funcionários decidissem que cursos fazer. Isso criava insatisfação posterior, pois, após o curso, muitas vezes não havia promoções ou utilização do aprendido.

Quase meio século depois, as UCs não escapam dessa sina. A pesquisa da FIA mostra um enorme peso dado aos aspectos sociais nas UCs. Ao serem perguntados sobre os impactos dos cursos na sustentabilidade (resultados ambientais, sociais e econômicos), os respondentes apontaram a mais alta concordância justamente para os “resultados sociais”, obtendo média igual a 4,13 (em uma escala de 1 a 5), superior à média dos resultados econômicos, que foi igual a 4,05. Na Pesquisa EC 2009, as médias foram 3,5 e 3,56 , respectivamente.

Possivelmente, essa é uma das maiores vulnerabilidades das nossas UCs. Admitamos, as empresas devem preocupar-se com os problemas sociais. É inegável o papel das UCs no sentido de estimular a cidadania por parte dos funcionários, para que se construam empresas sólidas e competitivas. Mas ou é ingenuidade ou hipocrisia achar que vale a pena oferecer um curso em que o aproveitamento do que foi aprendido não seja seriamente considerado. Perde-se em eficiência e perde-se em equidade, pois haveria maneiras melhores de destinar recursos com intenção social. No limite, em vez do curso, poderiam entregar ao seu beneficiário o dinheiro que seria gasto. Se o treinamento não tiver consequências no processo produtivo, por que não?

Naturalmente, esse nexo entre curso e resultado pode não ser óbvio ou fácil de estabelecer. Nos cursos de chão de fábrica, é mais simples. Se a empresa não vai precisar de eletricistas, não há boas razões para que o pintor se matricule em um curso sobre esse assunto. Já um curso de ética empresarial para altos executivos é suficientemente amplo para que possa ser recomendado a quase todos. Mas, no meio do caminho, as justificativas para as decisões são frágeis.

\section{0 poleiro das Universidades Corporativas ainda é baixo}

É da natureza da UC ter que operar muitos dos seus cursos just-in-time. Ora, para que o curso seja cronometrado para a hora exata, é preciso que seus operadores estejam perfeitamente concertados com os fluxos de mudança da empresa.

Eis um teste simples: quanto tempo o gestor da UC leva para conseguir falar com o CEO da empresa? Se demora para conseguir agendar um horário, é forçoso reconhecer que a tal sincronização torna-se mais difícil.

A pesquisa da FIA mostrou que as UCs brasileiras não estão tão perto assim dos centros de poder. Essa pode ser uma de suas deficiências mais graves. Mas, obviamente, isso é uma generalização, baseada nas médias observadas. Na prática, umas falam mais com a alta direção, outras, menos.

Sendo assim, podemos supor que, em muitas, exista um certo descompasso entre o planejamento, as soluções de aprendizagem oferecidas e as atividades da empresa. Isso é sério.

Talvez uma das explicações para essa situação possa vir da própria pesquisa, quando sugere que os altos executivos não têm total clareza quanto aos papéis da UC. Possivelmente, prendem-se a noções peremptas, nascidas nas tradições mais rasteiras dos Centros de Treinamento. 


\section{Como são conduzidos os programas das Universidades Corporativas?}

A pesquisa já citada permite uma avaliação razoavelmente detalhada de como são oferecidos os cursos nas UCs brasileiras.

Em primeiro lugar, chama atenção a variedade de maneiras de condução. Não há uma solução padronizada, usando salas de aula, seminários ou o que seja. Toda a riqueza oferecida pelas novas tecnologias está sendo usada em algum lugar, em algum curso, sem que as formas mais tradicionais hajam sido abandonadas.

Nesse sentido, estão anos-luz à frente do ensino acadêmico, que sequer conseguiu usar computadores nas salas de aula.

Cerca de um terço dos cursos é a distância. As telefônicas e os bancos, com suas equipes espalhadas pelo território nacional, são ávidas usuárias de ensino a distância (EAD). Outras não precisam ou não aprenderam a manejar tais técnicas. Como grande generalização, diríamos que, dadas a amplitude territorial do Brasil e a boa experiência já dominada no EAD, faria sentido se essa proporção fosse ainda maior.

Um aspecto decepcionante foi a pequena internacionalização das UCs. Embora 33 das 60 empresas respondentes tenham atuação internacional, apenas 13 delas têm atividades de suas UCs em outros países. Em uma nação de tradição isolacionista, seria de se desejar que as melhores empresas dessem o bom exemplo da internacionalização. Mas não é o caso.

\section{Como nossas Universidades Corporativas se comparam com as de outros países?}

As principais referências internacionais para acompanhar as melhores práticas e tendências em termos de UC no mundo têm sido a Corporate University XChange (Estados Unidos) e, também, a Annick RenaudCoulon (França).

Anualmente, a Corporate University XChange, em parceria com a Gradua- te School of Education (GSE) da Universidade da Pensilvânia, realiza o Global Leadership Congress, na Filadélfia. No evento, são apresentados os temas mais atuais sobre educação corporativa, além de contar com intensa contribuição de executivos, relatando casos empresariais. Também é feita a cerimônia de premiação dos melhores casos do ano (Excellence \& Innovation Awards Celebration).

Os critérios utilizados para as categorias do prêmio são: (i) alinhamento estratégico, (ii) alianças e parcerias, (iii) lançamentos (novas UCS ou novos programas e produtos), (iv) desenvolvimento de liderança, (v) tecnologia aplicada ao aprendizado, (vi) marketing e branding e (vii) medição dos resultados.

A análise do survey realizado pela Corporate University Xchange - que é a base da premiação - apontou algumas práticas relevantes para o sucesso dos casos, tais como: (i) envolvimento dos líderes, (ii) realização de parcerias com universidades, (iii) EAD e (iv) medição de resultados, bem como a implantação do Balanced Scorecard, vinculado à UC.

Entre os casos que têm se destacado nos últimos anos, merecem menção: Accenture, Alstom University, Aon, AT\&T, Boeing, Cannon Design, Cisco Systems, CSC, Discover, General Motors, Hitachi, Infosys, HP, JetBlue, Kodak, MasterCard, McCain Foods Limited, McDonald's, Microsoft, Miller Coors, NASA, PayPal, Raytheon, Seagate, Tata Consultancy Services, The Ritz-Carlton Leadership Center, Turkcell ,Veterans Affairs Learning University (VALU) e Westinghouse.

A já mencionada UC da GE, fundada em Crotonville, ao norte da cidade de Nova lorque, em 1956, pelo então CEO, Ralph Cordiner, sem dúvida, continua sendo a grande referência quando se fala no assunto. Portanto, tomemos apenas a GE, por ilustrar os píncaros a que pode chegar uma entidade desse tipo. Duas diferenças chamam a atenção, ouvindo as conferências de seus representantes.
A primeira é a ênfase na produtividade. 0 programa vai na jugular: se aumenta a produtividade, vai ser executado; se é apenas interessante, lixo. Qualquer que seja a situação, o casamento da oferta com a procura é uma busca obsessiva. Nada mais conta seriamente.

A segunda é o papel de inspirar e catalisar mudanças institucionais. A UC da GE está encarregada de proclamar os valores e expectativas da empresa com relação aos seus funcionários e aos seus destinos. Crotonville estabelece o currículo de liderança e é o coração da cultura GE. Claramente, está no nível mais elevado da filogênese descrita anteriormente.

Annick Renaud-Coulon é responsável pela organização e realização do Global Council of Corporate Universities (GlobalCCU) e do GlobalCCU Awards, e tem sido a referência na França com relação ao tema. De acordo com a especialista, poucas são as empresas que vão bater na porta das universidades tradicionais para o desenvolvimento de parcerias. As universidades, por sua parte, muitas vezes desconhecem a existência e o alcance da operação das UCs.

Outro aspecto por ela destacado refere-se aos elementos importantes para aumentar a competitividade da França: integração dos pobres, gestão da diversidade cultural, boa convivência e responsabilidade social e ambiental. No que diz respeito à EAD, trata-se de uma prática crescente, vista como fundamental para manter as ações de formação diante de orçamentos cada vez mais enxutos.

Alguns outros casos de destaque encontram-se na França: Accor, Alstom, BIC, Carrefour, Danone, EDF, L'Oréal, Michelin, RATP, Saint Gobain, Thales e Véolia Environnement.

De modo geral, ao compararmos as práticas das UCs no Brasil com as experiências dos Estados Unidos e França, notamos que adoção de práticas de EAD é forte nos dois países, enquanto aqui ainda é in- 
cipiente, sobretudo tratando-se de um país de dimensões continentais.

0 estabelecimento de parcerias com universidades tradicionais é uma prática forte no Brasil e Estados Unidos, mas, surpreendentemente, ainda pouco expressiva na França, ao menos de acordo com palavras de Renaud-Coulon em seu site (fonte: http://www.renaud-coulon.com/index. html, consultado em 04.03.2013).

Os Estados Unidos enfatizam produtividade e foco em resultados. A França enaltece aspectos sociais e ambientais. Parece que, nesse contexto, nossas UCs pendem para as práticas francesas. Dado o nosso vezo assistencialista, não parece que a França seja o melhor modelo.

Embora haja sutis diferenças ao compararmos as melhores práticas das UCs no Brasil, nos Estados Unidos e na França, no que se refere à estruturação do currículo, de modo geral, pode-se dizer que, nos três países, os currículos são modelados com base em competências organizacionais. Ressalte-se que, nos casos estudados no Brasil, na Pesquisa EC 2012, de acordo com 68\% dos respondentes, os currículos são estruturados com base no mapeamento das competências organizacionais.

\section{CONCLUSÃO}

A vivência dos autores e a pesquisa da FIA permitem esboçar algumas generalizações. A primeira e mais importante é que as UCs brasileiras vão bem de saúde. A maioria está crescendo e seus orçamentos se expandem. Com isso, as empresas estão implicitamente mostrando contentamento com o seu desempenho.

Nos $55 \%$ em que se apontou aumento de orçamento (de 2011 para 2012), os motivos mais citados para justificá-lo foram: maior número de ações educacionais, mais funcionários na organização e ampliação da atuação da UC. Em 22\% das empresas, não houve variação de orçamento. Apenas para $23 \%$ houve redução. Os motivos mais citados para as reduções foram: restrição orçamentária, cenário econômico negativo e mudanças no modelo de gestão.

Embora não exista um banco de dados oficial, estima-se que hoje existam de 500 a 600 UCs brasileiras. Segundo dados da Pesquisa EC 2012, elas são bem financiadas, têm boas equipes dirigentes e $73 \%$ pertencem a empresas nacionais. Note-se que, na versão da pesquisa realizada em 2009, o percentual de empresas de capital nacional era de $67 \%$.

$E$, ao que tudo indica, vieram para ficar. Talvez a principal razão seja a universalização da necessidade de continuar estudando por toda a vida. Chamemos isso de educação permanente ou não, mas é uma resposta à velocidade de câmbio dos processos produtivos e organizativos, exigindo que as pessoas se ajustem a eles, ao longo de toda a sua vida profissional.

Vale a pena refletir sobre o elo entre a educação e o que acontece com nossas vidas profissionais. Ao deixar a escola e encontrar um emprego, o número de anos que passamos estudando é o mais forte determinante do que vamos ganhar. Quanto mais se estuda, mais o salário inicial é elevado. Se acreditamos que o contracheque reflete a nossa contribuição para a produtividade da empresa, estarão sendo remunerados os anos de estudo. Aliás, Adam Smith já dizia a mesma coisa.

Quem estudou pouco ou nada permanece a vida toda atolado no mesmo pagamento medíocre. Em contraste, para os que têm mais educação, ao longo da vida profissional, o salário pode duplicar ou triplicar. Esses aumentos são espantosamente maiores do que o benefício de entrar mais educado no mercado de trabalho - no caso, comparado com quem tem menos escolaridade.

As empresas remuneram a nossa capacidade de produzir. Se pagam cada vez mais, ao longo das nossas carreiras, se nosso salário segue crescendo, isso significa que nos tornamos mais produtivos, com 0 passar do tempo. É forçoso concluir que, de alguma forma, continuamos aprendendo. Ficamos mais educados, mesmo sem voltar à escola.

Visto de outra maneira, o que aprendemos na escola tem um uso imediato, mas é menos expressivo. Conta mais o que aprendemos depois. Logo, seja do ponto de vista individual, seja do da empresa, o aprendizado mais valorizado economicamente é aquele que se dá durante nossa vida profissional, não antes. Essa conclusão não é sem consequências.

Tudo que puder ser feito para maximizar nosso aprendizado ao longo da carreira se traduz em avanços nos rendimentos. Para começar, conta a qualidade da educação que tivemos. Não são quantos fatos decoramos, mas nossa capacidade de ler, escrever, pensar, decifrar o mundo ao nosso redor, identificar e encontrar soluções para problemas.

E, pela vida afora, dependemos da presença de tudo que possa facilitar, incentivar e promover o aprendizado, o máximo condizente com o nosso potencial. Se assim é, a missão mais nobre das UCs será exercer esse papel de catalisador do processo de aprendizado durante a vida profissional. Nos casos mais óbvios, isso inclui cursos. Contudo, como ilustrado pelo caso da GE, trata-se de desenvolver nos funcionários a vontade de aprender.

Ajudam os cursos, mentores, estágios ou grupos de discussão. Essa é a boa tese da educação permanente. Também funciona o esforço próprio, autodidata, de maneira totalmente informal. Mas tudo depende de uma curiosidade insaciável e de uma atitude de continuar fazendo perguntas e buscando respostas. 0 que importa é a busca incansável de modos de alimentar a nossa sede de conhecimentos e de buscar novas soluções. A UC é uma das ferramentas para expandir nosso horizonte de aprendizado. 